\title{
O Ensino de Língua Portuguesa e a Prova Brasil: reflexões sobre uma parceria entre universidade e Educação Básica
}

\author{
Bruno Alves PEREIRA** \\ Marcelo Medeiros da SILVA*
}

\begin{abstract}
* Mestre (2011) em Linguagem e Ensino pela Universidade Federal de Campina Grande (UFCG). Doutorando em Linguística pela Universidade Federal da Paraíba. Professor de Língua Portuguesa e Linguística do Centro de Ciências Humanas e Exatas (CCHE) da Universidade Estadual da Paraíba (UEPB). Contato: brunoapcg@bol.com.br.

** Doutor (2011) em Letras pela Universidade Federal da Paraíba (UFPB). Professor de Literatura do Centro de Ciências Humanas e Exatas (CCHE) e do Programa de Pós-Graduação em Formação de Professores, ambos da Universidade Estadual da Paraíba (UEPB). Contato: marcelomedeiros_silva@yahoo.com.br.
\end{abstract}

\begin{abstract}
Resumo:
Este trabalho, que focaliza um conjunto de ações desenvolvidas por seus autores, professores de uma universidade pública estadual em um campus no interior da Paraíba, em parceria com a Secretaria de Educação de um município da região atendida por essa instituição de ensino superior, foi guiado por duas questões: i) que parcerias têm sido estabelecidas entre a universidade e a Educação Básica em torno da Prova Brasil de Língua Portuguesa?; e ii) que reflexões acerca do ensino dessa disciplina e da formação de professores têm sido possibilitadas por essa parceria? $\mathrm{Na}$ revisão teórica, partindo de estudos que focalizam a constituição da disciplina Português na Educação Básica (SOARES, 2002; PIETRI, 2003; BUNZEN, 2011), buscamos evidenciar a relação da Prova Brasil com o discurso da mudança no ensino dessa disciplina, surgido na década de 70 do século XX. As análises apresentadas evidenciam a importância das ações de ensino, pesquisa e extensão desenvolvidas pela universidade na diminuição dos impactos que a política neoliberal de avaliação exercida pelo instrumento Prova Brasil pode ter no ensino de Língua Portuguesa e na formação de professores.
\end{abstract}

\section{Palavras-chave:}

Prova Brasil. Universidade. Educação Básica.

Signum: Estudos da Linguagem, Londrina, v. 23, n. 1, p. 80-95, abr. 2020 


\title{
O Ensino de Língua Portuguesa e a Prova Brasil: reflexões sobre uma parceria entre universidade e Educação Básica
}

\author{
Bruno Alves Pereira; Marcelo Medeiros da Silva
}

\section{INTRODUÇÃO}

Este trabalho buscou registrar as ações de ensino, de pesquisa e de extensão desenvolvidas por seus autores - professores de um curso de Licenciatura em Letras em uma universidade estadual no Nordeste brasileiro - em parceria com escolas de Educação Básica em torno da Prova Brasil de Língua Portuguesa. De modo específico, nosso intento foi responder a duas questões: i) que parcerias têm sido estabelecidas entre a universidade e a Educação Básica em torno dessa avaliação de larga escala?; e ii) que reflexões acerca do ensino dessa disciplina e da formação de professores têm sido possibilitadas por essa parceria?

Criada no contexto das políticas neoliberais, ${ }^{1}$ que, teoricamente, teriam como foco a qualidade da educação, medida a partir de resultados numéricos (UFMG, 2011), a Prova Brasil avalia conhecimentos de Língua Portuguesa e Matemática e é aplicada, nos anos ímpares, aos alunos de $5^{\circ}$ e $9^{\circ}$ anos do Ensino Fundamental. Segundo o discurso governamental, essa avaliação de larga escala tem dois principais objetivos: “a) contribuir para melhoria da qualidade do ensino, redução de desigualdades e democratização da gestão do ensino público" e "b) buscar o desenvolvimento de uma cultura avaliativa que estimule o controle social sobre os processos e resultados do ensino" (BRASIL, 2008, p. 8).

O desempenho dos alunos nessa avaliação e o fluxo escolar, medido por meio da porcentagem de aprovações e de repetências, são os dois indicadores utilizados para estabelecer o Índice de Desenvolvimento da Educação Básica (IDEB), cujo objetivo seria identificar os municípios e as escolas que apresentam maior fragilidade escolar.

Os dados aqui analisados foram coletados e gerados ${ }^{2}$ entre os anos de 2015 e 2019 no âmbito de nossas ações de ensino, pesquisa e extensão como professores do Centro de Ciências Humanas e Exatas (CCHE) da Universidade Estadual da Paraíba (UEPB), localizado na cidade de Monteiro, a $305 \mathrm{~km}$ da capital do estado da Paraíba. Essas ações foram desenvolvidas em parceria com a Secretaria de Educação de um município da região na qual está localizado o CCHE.

De modo a responder às questões postas neste estudo a partir da análise desses dados, organizamos este artigo em seis partes. Após essa introdução, a partir das contribuições de autores que se dedicaram ao estudo da constituição da disciplina de Língua Portuguesa, relacionamos o surgimento da Prova Brasil com o "discurso da mudança nas concep̧̧ões de linguagem e no ensino de língua materna" (PIETRI, 2003, p. 9). Na sequência, iniciamos a análise das ações, observando experiências de ensino em torno da Prova Brasil realizadas por duas professoras em formação inicial e registradas em relatórios de estágio supervisionado.

A análise continua nas duas seções seguintes. Em "A universidade vai à escola pública em tempos de avaliação de larga escala", refletimos sobre um processo, ocorrido no ano de 2017, de formação de professores

\footnotetext{
${ }^{1}$ De modo sintético, o neoliberalismo pode ser entendido como um posicionamento econômico que defende a liberdade do mercado e a diminuição da intervenção do Estado. Esse posicionamento tem implicações em diversos setores da vida cotidiana, como na Educação (GENTILI, 1999).

${ }^{2}$ Certificado de Apresentação de Apreciação Ética: 87863018.3.0000.5187.
} 
para abordagem da Prova Brasil em sala de aula, ministrado pelos autores deste trabalho a pedido da Secretaria de Educação do munícipio parceiro. Em "O fortalecimento da parceria”, a análise volta-se para as ações em torno dessa avaliação, desenvolvidas em 2019, no âmbito do Programa de Bolsas de Iniciação à Docência (PIBID) e da Residência Pedagógica (RP). Por fim, apresentamos nossas reflexões acerca da relação entre nossas ações e a disciplina de Língua Portuguesa e a formação de professores nos dias atuais.

\section{O Ensino de Língua Portuguesa entre o Final do Século XX e os Dias Atuais}

Nesta seção, buscamos apresentar, a partir das contribuições de Soares (2002), Pietri (2003) e Bunzen (2011), a relação que pode ser estabelecida entre três aspectos relacionados ao ensino de Língua Portuguesa na Educação Básica: o "discurso da mudança nas concep̧̧ões de linguagem e no ensino de língua materna" (PIETRI, 2003, p. 9), surgido no final dos anos 70 do século XX, a compreensão dos setores acadêmico e governamental sobre o ensino dessa disciplina nos dias atuais e a matriz de referência da Prova Brasil.

Segundo os estudos mencionados, entre final dos anos 70 e início dos anos 80, a organização e os fundamentos da disciplina Português advindos, respectivamente, do período da ditadura militar e da Teoria da Comunicação, passaram a sofrer diversas críticas. Surge então, paulatinamente, o discurso da mudança que, no contexto dos movimentos pela redemocratização política, vai propor uma configuração para a disciplina de Língua Portuguesa a partir das compreensões sobre língua(gem) que, à época, estavam em construção nas diversas áreas da Linguística (Análise do Discurso, Linguística Textual, Sociolinguística, entre outras). Essas compreensões aparecem, nesse período, em diversas produções acadêmicas, a exemplo de $O$ Texto na Sala de Aula, coletânea organizada por João Wanderley Geraldi (2011), cuja primeira edição data de 1984.

Desse livro, destacamos o texto "Unidades básicas do ensino de português", de autoria do próprio Geraldi, cuja primeira versão é de 1981. Nele, o autor defende uma proposta de ensino de Português para os anos finais do nível fundamental (da $5^{\mathrm{a}}$ à $8^{\mathrm{a}}$ série na nomenclatura usada à época) numa perspectiva interacionista, cujo objeto central seria o texto, e estaria dividida em três eixos: "prática de leitura de textos", "prática de produção de textos" e "prática de análise linguística".

Mais de uma década depois, em 1998, o documento governamental Parâmetros Curriculares Nacionais (PCN) (BRASIL, 1998) retoma explicitamente, como demonstra uma nota de rodapé, as contribuições de Geraldi para propor que os conteúdos da disciplina de Língua Portuguesa se articulem em torno de dois eixos: “uso da língua oral e escrita” e "reflexão sobre língua e linguagem”. Conforme, é possível visualizar na Figura 1, na próxima página, reproduzida dos PCN, o eixo "uso" compreenderia as práticas de escuta, leitura e produção de textos; já o eixo "reflexão" contemplaria a prática de análise linguística. Desse modo, o discurso da mudança torna-se também um discurso governamental.

A partir da publicação desse documento, o modo de organização do ensino de Língua Portuguesa em eixos passou a ser divulgado em estudos acadêmicos, na formação de professores, em materiais didáticos e, inclusive, em outras publicações do Ministério da Educação. Nesse processo, foi consolidando-se, no sensocomum e na própria academia, a ideia de que os eixos do ensino de Língua Portuguesa seriam quatro - leitura, escrita, oralidade e análise linguística - e não dois - uso e reflexão. Essa ideia ganha tanta aceitação que, na Base Nacional Comum Curricular (BNCC) (BRASIL, 2017), publicada no final de 2017, propõe-se que o ensino da disciplina em questão seja feito em quatro eixos: "leitura", "produção de textos", "oralidade" e "análise linguística/semiótica".

Conforme ressalta Bunzen (2011, p. 904), a publicação dos PCN está relacionada a outro processo que impacta o ensino de Língua Portuguesa entre o final do século XX e os dias atuais: "o estabelecimento sistemático de avaliações em rede da educação básica”. Nas primeiras páginas do documento governamental Prova Brasil - Ensino Fundamental: matrizes de referência, tópicos e descritores (BRASIL, 2008), é possível identificar 
diversas menções aos PCN. Ao historicizar a avaliação de larga escala em questão, o documento afirma que a matriz de referência, criada em 1997, foi reformulada para adequar-se aos PCN em 2001. Na sequência, o documento apresenta conceitos elaborados no âmbito do discurso da mudança, como ensino de língua numa perspectiva discursiva-interacionista e texto e gênero como objeto e unidade da disciplina Língua Portuguesa na Educação Básica, respectivamente.

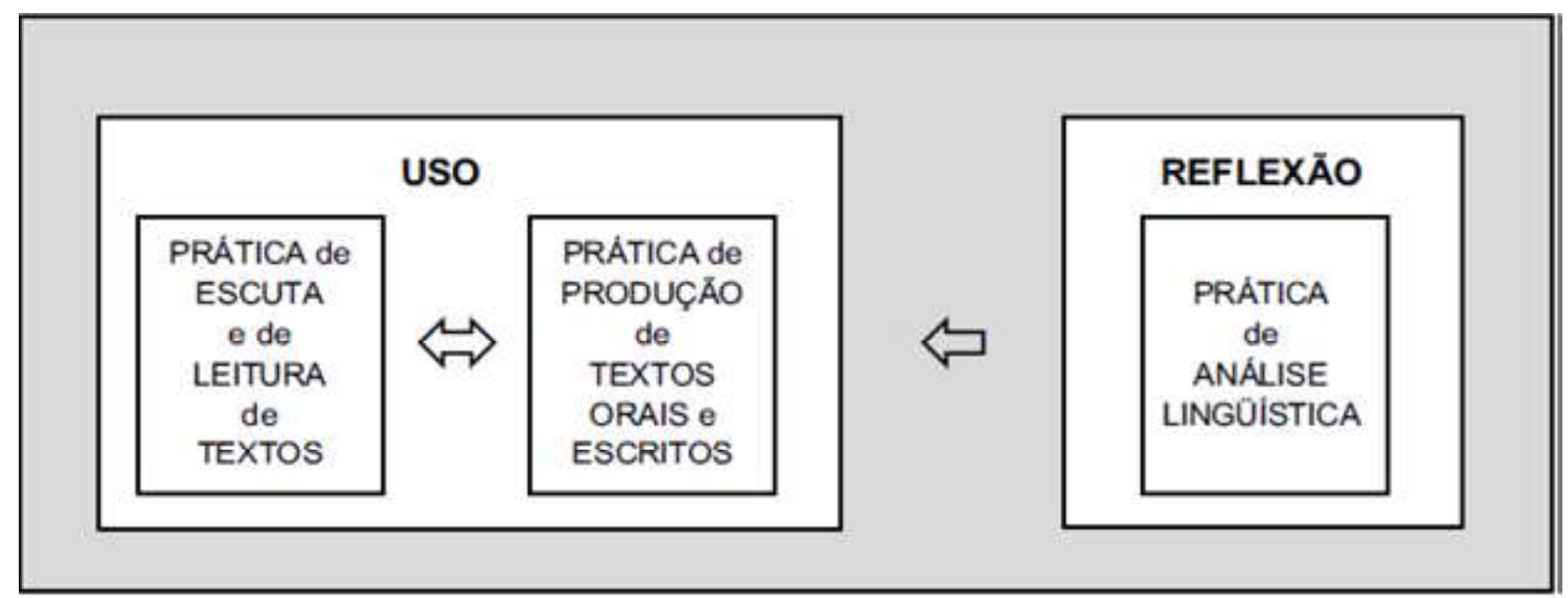

Fonte: Brasil, 1998, p. 35.

Figura 1 - O discurso governamental sobre a organização do ensino de Língua Portuguesa

A matriz para a disciplina em questão apresentada em Prova Brasil - ensino fundamental está dividida em seis partes denominadas tópicos, conforme evidenciado na coluna “Tópicos da Prova Brasil” no Quadro 1. Cada um desses tópicos abrange um conjunto de descritores entendidos como "uma associação entre conteúdos curriculares e operações mentais desenvolvidas pelo aluno, que traduzem competências e habilidades" (BRASIL, 2008, p. 18).

É possível associar os tópicos e, consequentemente, os descritores a determinadas áreas da Linguística que aparecem mencionadas no texto de Soares (2002) como perspectivas teóricas que influenciaram a constituição da disciplina de Língua Portuguesa no final dos anos 70 e início dos anos 80. Assim, mais uma vez observa-se a influência no discurso da mudança na Prova Brasil. Vejamos, no Quadro 1, uma síntese da organização da matriz da avaliação em questão.

Quadro 1 - Perspectivas teóricas subjacentes aos tópicos e descritores da Prova Brasil

\begin{tabular}{|c|c|c|}
\hline Tópicos da Prova Brasil & $\begin{array}{l}\text { Quantidade de descritores na } \\
\text { matriz do } 9^{\circ} \text { ano }\end{array}$ & Perspectiva teórica subjacente \\
\hline (I) Procedimentos de leitura & 5 & Leitura em uma perspectiva interacionista \\
\hline $\begin{array}{l}\text { (II) Implicações do suporte, do gênero e/ou } \\
\text { do enunciador na compreensão do texto }\end{array}$ & 2 & \multirow{3}{*}{ Linguística Textual } \\
\hline (III) Relações entre textos & 2 & \\
\hline $\begin{array}{l}\text { (IV) Coesão e coerência no processamento do } \\
\text { texto }\end{array}$ & 7 & \\
\hline $\begin{array}{l}\text { (V) Relações entre recursos expressivos e } \\
\text { efeitos de sentido }\end{array}$ & 4 & Análise do Discurso \\
\hline (VI) Variação linguística & 1 & Sociolinguística \\
\hline
\end{tabular}

Fonte: Elaborado pelos autores. 
Ao tópico I da matriz, intitulado "Procedimentos de leitura", está subjacente a perspectiva interacionista de leitura, que compreende que o(s) sentido(s) do texto são reconstruídos por um leitor a partir das marcas deixadas pelo escritor/produtor (KOCH; ELIAS, 2008). Entre os cinco descritores desse tópico encontra-se o de número 6, que compreende a identificação do tema de um texto.

Três tópicos - "Implicações do suporte, do gênero e/ou do enunciador na compreensão do texto", "Relações entre textos" e "Coesão e coerência no processamento do texto", que juntos abrangem pouco mais da metade dos descritores da matriz, podem ser relacionados à área da Linguística Textual, que se ocupa dos fenômenos envolvidos na produção e na recepção dos textos (SOARES, 2002; BENTES, 2011).

O descritor 12, pertencente ao tópico II, explora a identificação da finalidade de textos de diferentes gêneros. Os dois descritores do tópico III trabalham com a noção de intertextualidade, fundamental nos estudos da Linguística Textual. Os processos de referenciação e de conexão estão presentes nos descritores do tópico IV.

O tópico $\mathrm{V}$, que possui quatro descritores, sofre influência dos estudos da Análise do Discurso que, em linhas gerais, ocupam-se dos efeitos de sentido decorrentes de escolhas linguísticas (MUSSALIM, 2012). Por fim, a Sociolinguística, que estuda a relação entre linguagem e sociedade (ALKMIM, 2011), é a área subjacente ao único descritor do tópico VI, "Variação linguística".

Nas seções seguintes, discutimos a relação discurso da mudança e Prova Brasil nas ações de ensino, pesquisa e extensão desenvolvidas na parceria universidade e Educação Básica.

\section{Duas Professoras em Formação Inicial na Linha de Frente}

Nesta seção, focalizamos duas intervenções desenvolvidas pelas professoras em formação Rosa e Margarida, ${ }^{3}$ em turmas do $9^{\circ}$ ano do Ensino Fundamental em escolas da rede municipal parceira, nos anos de 2015 e 2017, respectivamente. ${ }^{4}$ À época do desenvolvimento das ações, essas duas professoras em formação inicial eram alunas da disciplina Estágio Supervisionado II do curso de Letras - Língua Portuguesa do CCHE, ministrada por um dos autores deste texto, e bolsistas de um programa de extensão coordenado por esse mesmo professor.

Nosso interesse principal aqui é descrever os projetos de interação ou projetos didáticos mobilizados por Rosa e Margarida e seus processos de elaboração. Proveniente da obra Estudo da Lingua Falada e Aula de Lingua Materna: uma abordagem processual da interação professor-aluno, de Maria de Lourdes Meirelles Matêncio (2001), o termo projeto pode ser entendido como um conjunto de estratégias didático-discursivas utilizadas para obter a finalidade de uma ou de um conjunto de aulas. Já estratégia é compreendida como "o que o professor faz ou requisita discursivamente” para atingir essa finalidade (PEREIRA, 2011, p. 18).

Para descrever esses projetos, recorremos inicialmente aos relatórios elaborados por Rosa e Margarida para a disciplina Estágio Supervisionado II, cujo foco era a intervenção nos anos finais do Ensino Fundamental. Em seguida, elaboramos sinopses ${ }^{5}$ que permitiram a identificação das estratégias didático-discursivas que compõem os projetos dessas duas profissionais.

Antes de apresentar as estratégias mobilizadas, é necessário descrever o processo de elaboração dos projetos didáticos de Rosa e Margarida. Essas duas profissionais aplicaram simulados da Prova Brasil de

\footnotetext{
${ }^{3}$ Nomes fictícios.

${ }^{4}$ Para uma análise ampliada dessas intervenções, conferir Silva, F. K. L. (2019).

${ }^{5}$ Criada por pesquisadores da equipe de Didática de Línguas da Faculdade de Psicologia e Ciências da Educação da Universidade de Genebra, na Suíca, a sinopse é um instrumento metodológico utilizado para permitir uma visão geral de um conjunto de aulas (SCHNEUWLY; DOLZ, 2009).
} 
Língua Portuguesa em todas as turmas de $9^{\circ}$ ano da rede municipal parceira, como parte de suas ações no projeto de extensão do qual participavam, tendo em vista identificar os descritores mais e menos dominados pelos discentes. De posse dessas informações, Rosa e Margarida planejaram intervenções cujo objetivo era promover o desenvolvimento das habilidades relacionadas aos descritores que se mostravam ainda problemáticos tanto para os alunos dos $9^{\circ}$ anos daquela rede municipal de modo geral quanto para os discentes das turmas específicas nas quais essas profissionais iriam atuar.

Rosa, que realizou a sua intervenção em 2015, focalizou os gêneros crônica, notícia e reportagem e quatro descritores: os de número 2 (estabelecer relações entre as partes de um texto, identificando repetições ou substituições que contribuem para a continuidade de um texto), 6 (identificar o tema de um texto), 13 (identificar as marcas linguísticas que evidenciam o locutor e o interlocutor de um texto) e 20 (reconhecer diferentes formas de tratar uma informação na comparação de textos que tratam do mesmo tema, em função das condições em que ele foi produzido e daquelas em que será recebido). Margarida, que realizou a sua experiência de ensino em 2017, abordou dois gêneros, a notícia e a reportagem, e dois descritores: os de número 6, de modo semelhante à Rosa, e 15 (estabelecer relações lógico-discursivas presentes no texto, marcadas por conjunções, advérbios etc.).

No Quadro 2, a seguir, é possível visualizar as estratégias didático-discursivas que compõem os projetos de interação para abordagem da Prova Brasil em sala de aula.

Quadro 2 - Os projetos didáticos de duas professoras em formação para abordagem da Prova Brasil

\begin{tabular}{|c|c|}
\hline Rosa & Margarida \\
\hline $\begin{array}{l}\text { - Leitura e discussão de um exemplar do gênero crônica; } \\
\text { - Leitura e discussão de quatro exemplares do gênero } \\
\text { crônica e identificação dos temas e níveis de linguagem } \\
\text { dos textos lidos; } \\
\text { - Exposição sobre o tema variação linguística e leitura e } \\
\text { discussão de um exemplar do gênero notícia; } \\
\text { - Leitura e discussão de um exemplar do gênero crônica e } \\
\text { identificação do tema e do nível de linguagem do texto } \\
\text { lido; } \\
\text { - Identificação das diferentes formas de tratar o mesmo } \\
\text { tema em textos diferentes; } \\
\text { - Leitura de textos e identificação dos temas e níveis de } \\
\text { linguagem; } \\
\text { - Exposição sobre os processos de repetição e } \\
\text { substituição de palavras no texto. }\end{array}$ & 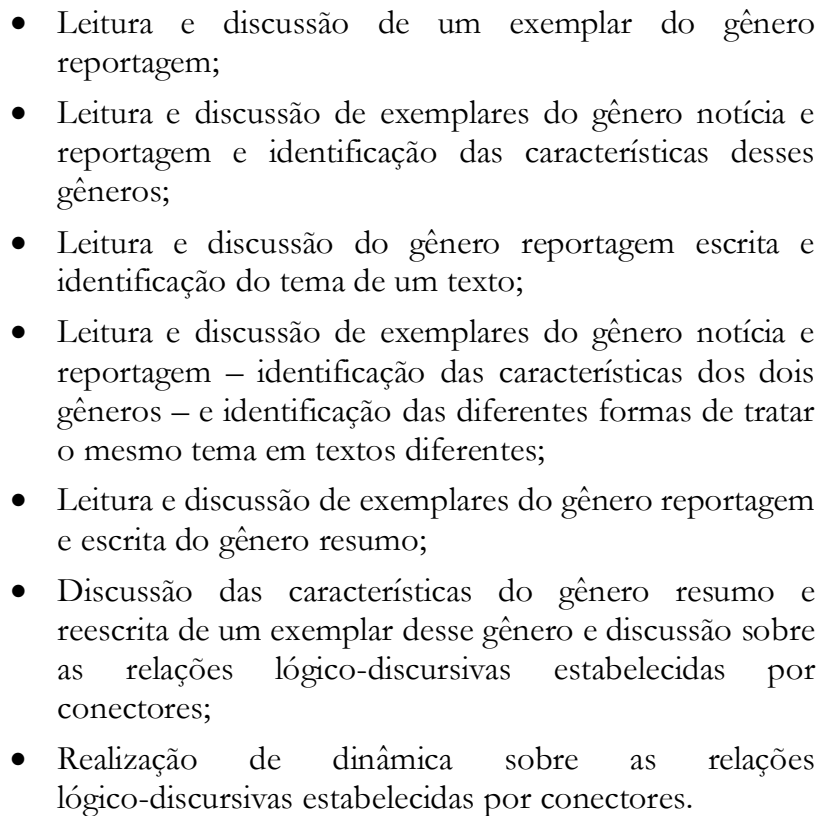 \\
\hline
\end{tabular}

Fonte: Adaptado de Silva, F., 2019.

O projeto de Rosa, que durou 13 horas-aula, mobilizou seis estratégias didático-discursivas, sendo algumas delas utilizadas mais de uma vez. Desse projeto, escolhemos exemplificar o desenvolvimento da estratégia "identificação das diferentes formas de tratar o mesmo tema em textos diferentes", mobilizada na nona aula da intervenção.

Após discutir as características da linguagem utilizada em interações menos monitoradas na internet e, consequentemente, abordar o descritor 13 (identificar as marcas linguísticas que evidenciam o locutor e o interlocutor de um texto), Rosa levou para sala de aula dois textos: a reportagem, disponível na internet, "Uso 
do internetês pode prejudicar futuro profissional, diz especialista” e a crônica “\#s de comunikssaum” presente no livro Estive pensando, de Antonio Prata.

Feita a leitura dos textos, Rosa guiou os alunos na identificação do tema principal e dos níveis de linguagem, o que possibilitou que eles reconhecessem que um mesmo tema, o internetês, pudesse ser abordado de, pelo menos, duas formas: de modo humorístico e em internetês, na crônica, e de maneira mais formal, na reportagem. Nas aulas seguintes, a estratégia continuou a ser mobilizada através da leitura e da discussão dos gêneros crônica e notícia, concretizando um trabalho em torno do descritor 20, qual seja, reconhecer diferentes formas de abordar uma informação na comparação de textos que tratam do mesmo tema, em função das condições em que ele foi produzido e daquelas em que será recebido.

As estratégias mobilizadas por Rosa, especificamente a leitura e discussão de gêneros diversos e a identificação dos temas e níveis de linguagem dos textos lidos, evidenciam uma tentativa de combinar práticas de leitura, através da identificação das relações intertextuais entre textos, e práticas de análise linguística, por meio da observação das relações entre marcas linguísticas e locutor/interlocutor dos textos.

Do projeto de Margarida, que se estendeu por 19 horas-aula e mobilizou dez estratégias didáticodiscursivas, sendo algumas acionadas mais de uma vez, como na experiência de Rosa, optamos por exemplificar duas estratégias utilizadas concomitantemente: "leitura e discussão de exemplares do gênero reportagem" e "escrita do gênero resumo".

$\mathrm{Na}$ décima primeira e décima segunda aulas da intervenção, Margarida levou para a sala duas reportagens originalmente publicadas em revistas impressas que tematizam a violência contra a mulher. Após leitura e discussão das relações existentes entre os textos, Margarida dividiu a turma em dois grupos e estabeleceu, através do seguinte comando escrito, que cada um dos grupos ficaria responsável pela produção de um resumo de uma das reportagens lidas: "Suponha que alguém que está longe de vocês precisa receber as principais informações da reportagem lida. Pensando nisto, escreva em forma de resumo (10-15 linhas) sobre os assuntos abordados na reportagem".

Foi possível observar, nessas duas aulas de Margarida, um trabalho com o descritor 6: identificar o tema de um texto. Diferentemente da Prova Brasil, que testa essa habilidade por meio de questões de múltipla escolha, Margarida optou por explorá-la através da prática de escrita do gênero resumo. Desse modo, essa professora em formação inicial desenvolve um trabalho conjunto entre práticas de leitura e de escrita, o que revela uma apropriação do discurso da mudança (PIETRI, 2003; GERALDI, 2011).

A observação dos projetos didáticos de Rosa e Margarida permitiu identificar duas propostas de ensino de Língua Portuguesa que contemplam o trabalho com os descritores da Prova Brasil em uma perspectiva que parte do texto, conforme preconizam os discursos acadêmicos e governamentais sobre o ensino dessa disciplina. Ao observar não só os projetos em si, mas também os seus processos de elaboração, verificamos as relações estabelecidas entre ações de ensino, pesquisa e extensão da universidade, especificamente da formação de professores, em favor da Educação Básica.

Como demonstrado nesta seção, esse processo de colaboração começa, em 2015, com poucos participantes - a estagiária/bolsista e o professor universitário, mas, posteriormente, tem seus colaboradores e ações intensificadas, conforme evidenciado a seguir.

\section{A Universidade Vai à Escola Pública em Tempos de Avaliação em Larga Escala ${ }^{6}$}

No primeiro mês de 2017, o CCHE recebeu um pedido da Secretaria de Educação da rede municipal em questão para organizar um processo de formação dos professores de Língua Portuguesa e de Matemática

\footnotetext{
${ }^{6}$ Título principal do livro organizado por José Licínio Backes e Ruth Pavan e publicado pela editora Mercado de Letras em 2018.
} 
para auxiliá-los no processo de abordagem da Prova Brasil em sala de aula. Acatamos o pedido e iniciamos os trabalhos com a palestra "A Prova Brasil: 'O que eu tenho a ver com isso?" na jornada pedagógica que marcava o começo do ano escolar. Nessa ocasião, discutimos, com os professores de todos os níveis que atuam naquela rede, a organização dessa avaliação de larga escala e o impacto que ela pode exercer nas salas de aula. Além disso, apresentamos os resultados de dois levantamentos dos descritores de Língua Portuguesa mais e menos dominados pelos alunos daquela rede, que havíamos feito no âmbito dos nossos projetos de pesquisa e de extensão dos quais haviam participado as professoras Rosa e Margaria, conforme descrito na seção anterior.

Nas semanas seguintes, em acordo estabelecido com a Secretaria de Educação, foi acertado que a formação para os professores de Língua Portuguesa que atuavam nos anos finais do Ensino Fundamental seria a cada quinze dias, às quintas-feiras, das $19 \mathrm{~h}$ às $21 \mathrm{~h} 30,{ }^{7}$ nas dependências de uma das escolas da rede municipal localizada no centro da cidade. Houve, portanto, uma nova organização no processo de colaboração. Parafraseando o título do livro organizado por Backes e Pavan (2018) e desta seção: a universidade vai à escola pública em tempos de Prova Brasil. Antes do início de 2017, já frequentávamos as escolas da rede municipal em nossas ações de ensino, pesquisa e extensão; porém, a partir daquela jornada, essas visitas aumentaram em frequência e em qualidade.

Organizamos os três primeiros encontros para apresentar as bases teórico-metodológicas da avaliação (cf. "O ensino de Língua Portuguesa do final do século XX aos dias atuais") e identificar quais eram as expectativas e demandas do grupo de, aproximadamente, vinte professores. Dos encontros posteriores a esse processo de aproximação, selecionamos três momentos para discutir aqui.

O primeiro momento selecionado diz respeito à relação estabelecida entre o planejamento das aulas e os descritores da Prova Brasil. Nos nossos primeiros encontros nas quintas-feiras à noite, perguntamos aos professores se poderíamos participar, como observadores, de uma das sessões de preparação de aulas que ocorriam nas quintas-feiras em que não havia a formação destinada à Prova Brasil. O nosso intuito era compreender o processo de planejamento para que discutíssemos, nos nossos encontros, os diálogos que eram estabelecidos entre esse processo e a avaliação de larga escala em questão. Nessa observação, identificamos que as aulas nos anos finais do Ensino Fundamental seguiam essencialmente a proposta do livro didático que havia sido escolhido pela rede municipal para o triênio 2017-2019. Ao lado dos conteúdos, que seriam abordados ao longo de uma semana de aulas, os professores, a pedido da Secretaria de Educação, indicavam os descritores da Prova Brasil que seriam também explorados.

Ao observar esses planejamentos, verificamos algumas práticas que se apresentavam como problemáticas. Uma delas era a incompatibilidade entre o conteúdo e o(s) descritor(es). Como registra o material de apresentação da matriz de referência da Prova Brasil (BRASIL, 2008), alguns gêneros textuais são mais adequados do que outros à exploração de um dado descritor. Gêneros poéticos, por exemplo, são espécies de texto bastante apropriados para o trabalho com os descritores 17 (identificar o efeito de sentido decorrente do uso da pontuação e de outras notações) e 19 (reconhecer o efeito de sentido decorrente da exploração de recursos ortográficos e/ou morfossintáticos). No entanto, a utilização desses gêneros para tratar sistematicamente o descritor 15 (estabelecer relações lógico-discursivas presentes no texto, marcadas por conjunções, advérbios etc.) não parece ser a escolha mais sensata.

Essa relação entre o conteúdo e o(s) descritor(es) não era observada com detalhes pelos professores no processo de planejamento. Desse modo, a Prova Brasil parecia ser entendida como "um conteúdo a mais" dos já estabelecidos pelo livro didático. Além disso, alguns descritores apareciam repetidas vezes, enquanto outros nem eram mencionados.

${ }^{7}$ Nas outras duas quintas-feiras do mês, os professores reuniam-se para planejar as aulas que seriam ministradas. 
A observação do planejamento também permitiu identificar dois encaminhamentos metodológicos para abordagem da Prova Brasil que aconteciam naquela rede de ensino. Em um primeiro, denominado de "aulão", os professores, seguindo orientação da Secretaria de Educação, projetavam em sala de aula, através de computador e do aparelho de datashow, questões, geralmente reproduzidas do documento Prova Brasil ensino fundamental (BRASIL, 2008) ou de sites da internet. Essas questões eram lidas em voz alta pelo docente e os alunos deveriam indicar, por meio de placas, nas quais estavam as quatro primeiras letras do alfabeto, a alternativa correta. Em um segundo encaminhamento, as questões de múltipla escolha que focalizavam vários descritores apareciam em simulados que eram respondidos pelos alunos em sala de aula.

A observação desses dois encaminhamentos feita via planejamentos e relatos dos professores revela uma crença de que os alunos dominariam as habilidades e as competências subjacentes aos descritores através da resolução de questões, nos aulões e nos simulados, e dos comentários feitos pelos docentes, quando era possível uma discussão das respostas dos alunos. Essa configuração da disciplina Língua Portuguesa afasta-se do discurso da mudança (PIETRI, 2003) e aproxima-se da prática de ensino para o teste (VOLANTE, 2004). Ao invés de uma metodologia de uso e reflexão da língua(gem) via textos (GERALDI, 2011), que envolveria exposição dialogada e atividades de leitura/escuta, produção e análise linguística, os alunos eram estimulados essencialmente a desenvolver "macetes" que facilitassem a apresentação de respostas em curto espaço de tempo.

Feitas essas constatações, utilizamos alguns encontros de formação para discutir o que se mostrava problemático nos planejamentos e conseguimos, pelo menos, rever a incompatibilidade entre o(s) conteúdo(s) e o descritor. Foi quando sentimos a necessidade de dar um novo passo no processo de estudo da Prova Brasil. Embora não verbalizassem explicitamente, os professores davam indícios de que gostariam de ver exemplos de atividades para além das questões de múltipla escolha, que pudessem ser feitas em sala de aula para trabalhar com os descritores. Para discutir aqui esse momento da formação, trazemos, a seguir, o Exemplo 1.

\section{Exemplo 1}

\section{D6 - Identificar o tema de um texto}

Primeiramente, com base na observação das fotografias da reportagem "Vaqueiros", presentes no nosso livro didático, e nos títulos e subtítulos da reportagem, preencha a coluna "Minhas hipóteses sobre o assunto abordado" no quadro a seguir.

\begin{tabular}{|l|c|l|}
\hline \multicolumn{1}{|c|}{ Títulos e subtítulos } & $\begin{array}{c}\text { Minhas hipóteses sobre o } \\
\text { assunto abordado }\end{array}$ & Assunto abordado \\
\hline Vaqueiros & & \\
\hline Boné e camisa & & \\
\hline Bater esteira & & \\
\hline Acampanhamento & & \\
\hline Reconhecimento & & \\
\hline
\end{tabular}

Agora, realize a leitura da reportagem, que se estende da página 108 à 112, com o objetivo de identificar se as hipóteses levantadas por você sobre o assunto abordado se confirmam ou não. Após a leitura das cinco partes da reportagem, preencha a coluna "Assunto abordado".

Para concluir, escreva, com, no mínimo, 2 (duas) e, no máximo, 4 (quatro) linhas, o assunto abordado na reportagem "Vaqueiros", publicada na revista "Muito". (...)

Fonte: Acervo dos autores. 
No Exemplo 1 está a reprodução de um trecho de uma atividade elaborada no contexto de um de nossos projetos de extensão que, posteriormente, foi discutida em um dos encontros de formação. Ela é uma adaptação de um encaminhamento de leitura disponível no livro didático do $9^{\circ}$ ano, em um capítulo destinado ao estudo do gênero reportagem.

De acordo com o enunciado, os discentes deveriam levantar hipóteses sobre os subtemas de uma longa reportagem, intitulada "Vaqueiros", a partir da observação das figuras e dos subtítulos. Após a leitura, os alunos deveriam indicar se as hipóteses levantadas se confirmavam ou não, através da indicação do assunto abordado em cada uma das seções da reportagem. Por fim, havia a requisição de elaboração de um resumo do texto lido. O objetivo da atividade - que poderia se estender por, provavelmente, três aulas, tendo em vista a extensão da reportagem - era trabalhar estratégias de identificação de subtemas do texto como um procedimento para uma compreensão global do tema, habilidade subjacente ao descritor 6 (identificação do tema de um texto).

A apresentação dessa e de outras atividades foi bem recebida pelos professores, que puderam perceber, talvez pela primeira vez, a possibilidade de explorar os descritores da Prova Brasil de Língua Portuguesa de modo distinto do feito através das questões de múltipla escolha que já aparecem no material publicado pelo governo federal (BRASIL, 2008).

O terceiro momento que escolhemos para discutir nesta seção diz respeito à produção de questões pelos professores participantes para serem utilizadas nas avaliações das escolas da rede. No ano de 2017, principalmente nos três primeiros bimestres - os que antecedem a aplicação da Prova Brasil -, os professores realizavam pelo menos dois tipos de prova: uma delas denominada avaliação e a outra, simulado. As primeiras edições destes últimos eram compostas principalmente por questões de múltipla escolha retiradas do material publicado pelo governo federal e de sites da internet (SILVA, D., 2009). Sabendo disso, propusemos aos docentes utilizar o tempo destinado às formações, nas quintas-feiras, para a produção de questões que pudessem ser utilizadas tanto nesses simulados quanto nas avaliações. A seguir, apresentamos um trecho dessas produções dos professores.

\section{Exemplo 2}

2) No fragmento: "Se não há povo participante em quantidade e, sobretudo, em qualidade, que lhe dê corpo e alma, desfilará um ajuntamento de virtuose, ou pseudo-virtuose, não frevo", a conjunção destacada exprime ideia de
A) comparação
B) conclusão
C) condição
D) consequência

3) Em "A gente tá fazendo uma perversidade com ele", temos predominância do uso da linguagem
A) coloquial
B) culta
C) científica
D) não-verbal

Fonte: Acervo dos autores.

No Exemplo 2, estão duas das seis questões de uma das avaliações elaboradas para os $9^{\text {os }}$ anos das escolas da rede. Pensadas de acordo com o padrão estabelecido pela Prova Brasil - formato múltipla escolha e com a alternativa certa completando a sentença presente do enunciado de extensão curta -, as questões 2 e 3 apresentadas no Exemplo 2 exploram, respectivamente, os descritores 15 (estabelecer relações lógico-discursivas presentes no texto, marcadas por conjunções, advérbios etc.) e 13 (identificar as marcas 
linguísticas que evidenciam o locutor e o interlocutor de um texto). Os fragmentos apresentados entre aspas, nos enunciados, faziam parte de textos presentes no livro didático que eram parcialmente reproduzidos nas avaliações.

Infelizmente, nos encontros de formação, não foi possível destinar um espaço para a elaboração de atividades que fossem utilizadas na interação em sala de aula e não somente em avaliações/simulados. Mesmo não alcançando esse objetivo, consideramos bastante produtivo o momento destinado à produção de questões como as apresentadas no Exemplo 2, pois, nesse processo, os professores demonstravam se, de fato, haviam compreendido os aspectos teórico-metodológicos subjacentes à Prova Brasil discutidos anteriormente nos encontros. A elaboração das questões naquele momento também contribuiu para a construção de uma prática que evitava a cópia de produções disponíveis na internet.

A possibilidade de abordar a Prova Brasil em sala de aula não mais como "um conteúdo a mais" dos já estabelecidos pelo livro didático não conseguiu ser pensada a contento nos encontros de formação e só pôde ser experienciada no ano de 2019, como descrito na seção seguinte.

\section{O Fortalecimento da Parceria}

Em 2018, assumimos as coordenações de Língua Portuguesa do Programa de Bolsas de Iniciação à Docência (PIBID) e da Residência Pedagógica (RP) no CCHE da UEPB. Cada um desses programas contava com a participação de 24 professores em formação inicial e três docentes da Educação Básica, que atuavam como supervisores dos licenciandos. Todos na condição de bolsistas. Após um processo, que se estendeu de agosto de 2018 a fevereiro de 2019, de estudo e observação da realidade escolar, demos início ao planejamento das intervenções a serem realizadas pelos licenciandos.

Nesse momento, verificamos que cinco dos seis professores da Educação Básica participantes dos programas mencionados atuavam em escolas da rede municipal, parceira de nossas ações desde 2015, e ministrariam aulas para turmas do $9^{\circ}$ ano. Diante desse cenário, observamos a possibilidade de dar continuidade à nova relação que tinha sido estabelecida com essa avaliação de larga escala em anos anteriores, principalmente no que concerne a repensar a configuração da disciplina de Língua Portuguesa, evitando o tratamento que era dispensado anteriormente pelos professores, a partir de orientações da Secretaria, à Prova Brasil.

Fizemos um novo levantamento dos descritores menos dominados pelos alunos a partir da aplicação de um simulado - a avaliação diagnóstica das habilidades de leitura (CARVALHO, 2018). De posse dos resultados, propusemos a esses cinco professores romper com a perspectiva que tinha o livro didático como organizador da sequência de conteúdos do ano escolar. Em seu lugar, entraria uma configuração, que, ao longo do ano, na perspectiva do discurso da mudança, focalizaria os descritores ainda não dominados pelos alunos. A proposta foi acatada pelos cinco professores com uma condição: nós, enquanto docentes da Universidade e coordenadores do PIBID e da RP, deveríamos apresentar a nova organização à Secretaria de Educação e esperar pela anuência desse departamento. Depois de algumas reuniões, o aval foi dado.

Em uma tarde de fevereiro de 2019, reunimos os professores em formação inicial que atuariam em turmas do $9^{\circ}$ ano e alguns dos docentes da Educação Básica para realizar o planejamento na perspectiva que temos defendido neste trabalho e que havia sido acatada pela Secretaria de Educação. No Exemplo 3, a seguir, apresentamos um trecho da versão final do planejamento para o $1^{\circ}$ bimestre do ano nessa perspectiva. 


\begin{tabular}{|c|c|c|c|}
\hline Descritores & Habilidades & $\begin{array}{l}\text { Objetos de } \\
\text { conhecimento }\end{array}$ & Data \\
\hline $\begin{array}{l}\mathrm{D} 12 \\
\mathrm{D} 13 \\
\mathrm{D} 4\end{array}$ & $\begin{array}{l}\text { Identificar a finalidade de textos de diferentes gêneros, bem } \\
\text { como das marcas linguísticas que evidenciam o locutor e o } \\
\text { interlocutor de um texto / Identificar informações implícitas }\end{array}$ & $\begin{array}{l}\text { Finalidade dos gêneros } \\
\text { textuais e variação } \\
\text { linguística }\end{array}$ & $\begin{array}{l}18 / 03 \text { a } 22 / 03 \\
(5 \text { dias/aula) }\end{array}$ \\
\hline $\begin{array}{l}\mathrm{D} 20 \\
\mathrm{D} 4\end{array}$ & $\begin{array}{l}\text { Reconhecer as diferentes formas de tratar uma informação na } \\
\text { comparação de textos que tratam do mesmo tema, em função } \\
\text { das condições em que ele foi produzido e daquelas em que } \\
\text { será recebido / Identificar informações implícitas }\end{array}$ & Intertextualidade & $\begin{array}{l}25 / 03 \text { a } 29 / 03 \\
(5 \text { dias/aula) }\end{array}$ \\
\hline $\begin{array}{l}\text { D9 } \\
\text { D4 }\end{array}$ & $\begin{array}{l}\text { Diferenciar as partes principais das secundárias em um texto } \\
\text { / Identificar informações implícitas }\end{array}$ & $\begin{array}{l}\text { Tópicos frasais de um } \\
\text { texto/ artigo de opinião }\end{array}$ & $\begin{array}{l}01 / 04 \text { a } 05 / 04 \\
(5 \text { dias/aula) }\end{array}$ \\
\hline $\begin{array}{l}\text { D21 } \\
\text { D4 }\end{array}$ & $\begin{array}{l}\text { Reconhecer as posições distintas entre duas ou mais opiniões } \\
\text { relativas ao mesmo fato ou ao mesmo tema / Identificar } \\
\text { informações implícitas }\end{array}$ & $\begin{array}{l}\text { Argumentação/ artigo } \\
\text { de opinião }\end{array}$ & $\begin{array}{l}08 / 04 \text { a } 12 / 04 \\
(5 \text { dias/aula) }\end{array}$ \\
\hline
\end{tabular}

Fonte: Acervo dos autores.

No trecho apresentado no Exemplo 3, há planejamento para quatro semanas do $1^{\circ}$ bimestre, nas quais seriam focalizados seis descritores. Um deles, o de número 4 (identificar informações implícitas), deveria ser explorado sempre que possível, por ser uma habilidade essencial em qualquer processo de produção de sentidos e cuja exploração não está atrelada a um dado gênero textual.

As duas primeiras semanas ficaram sob a responsabilidade dos professores em formação inicial. $\mathrm{Na}$ primeira, a proposta era o trabalho com a identificação da finalidade e do nível de linguagem de diferentes textos (descritores 12 e 13). Quando essas intervenções foram realizadas, presenciamos esses professores levarem exemplares de textos de diferentes gêneros orais e escritos para sala de aula para possibilitar reflexões sobre aspectos relacionados ao contexto de produção (autor, público-alvo, tema, finalidade etc.). Na segunda semana, os licenciandos exploraram a relação temática entre textos (descritor 20).

Na primeira semana ministrada pelos professores da Educação Básica que atuavam como supervisores dos licenciandos, o trabalho em torno da identificação dos temas e subtemas dos textos continuou, especialmente, explorando a habilidade de diferenciar as partes principais das secundárias (descritor 9). $\mathrm{Na}$ segunda semana ministrada por esses professores, iniciou-se um trabalho com o artigo de opinião em que diferentes descritores foram contemplados, a exemplo do 21, conforme é possível visualizar no Exemplo 3.

O trabalho com esse gênero, continuado pelos professores em formação inicial nas semanas seguintes, marca uma nova relação que foi estabelecida com o livro didático, e que precisa ser aqui ressaltada. $\mathrm{O}$ artigo de opinião não aparecia no início do material e, por esse motivo, provavelmente não seria objeto de ensino no começo do ano escolar. Porém, no dia de elaboração da primeira versão do planejamento, ao elencar o descritor 21 (reconhecer as posições distintas entre duas ou mais opiniões relativas ao mesmo fato ou ao mesmo tema) como uma das prioridades do $1^{\circ}$ bimestre, solicitamos que os presentes na reunião identificassem que gênero da ordem do argumentar presente no livro poderia ser focalizado para permitir o trabalho com aquele descritor. Depois de algumas discussões extremamente salutares, foi estabelecido que o trabalho seria em torno do artigo de opinião. Assim, inverteu-se uma lógica comum no planejamento daquela rede de ensino: antes, o conteúdo era estabelecido pelo livro didático e os professores buscavam, às vezes sem sucesso, atrelá-lo a um dado descritor; agora, a partir da identificação de uma habilidade não dominada pelos alunos, um descritor, verificava-se que conteúdo do material poderia ser explorado em sala de aula.

Nos meses que se seguiram às semanas apresentadas no Exemplo 3, houve retorno a alguns dos descritores cujas habilidades subjacentes ainda não haviam sido compreendidas pelos alunos, como também 
houve mudanças em algumas formas de planejamento. Como exemplo, podemos citar o aumento no período de tratamento de um dado conteúdo, de uma para duas semanas.

Nessa nova configuração da disciplina, a pedido da Secretaria de Educação, os simulados tiveram que continuar a ser realizados mensalmente. Por vezes, questionamos o argumento teórico-metodológico que sustentava a utilização desses simulados com tal frequência, porém não obtivemos respostas consistentes. Esse fato demonstra que algumas práticas que se opõem ao discurso da mudança no ensino de línguas são mantidas, apesar de esforços contrários, porque estão assentadas em uma longa tradição sob a responsabilidade de pessoas ou instituições que detêm o poder (SIGNORINI, 2007).

Um aspecto importante do contexto analisado nesta seção a ser ressaltado, e que nos fez acreditar e defender a concretização de uma nova configuração para o ensino, diz respeito ao aumento no número de envolvidos em nossas ações de ensino, pesquisa e extensão e às condições de trabalho que lhes foram dadas e que, embora não fossem perfeitas, possibilitavam, minimamente, a participação deles. Conforme mencionado, tanto licenciandos quanto professores da Educação Básica recebiam ajuda financeira em forma de bolsa para participar do PIBID e da RP e, consequentemente, das reuniões semanais nas quais eram discutidos os aspectos teórico-metodológicos do ensino de Língua Portuguesa na contemporaneidade e planejadas as intervenções. Sem essa bolsa, possivelmente nem professores nem licenciandos poderiam disponibilizar boa parte do seu tempo para as ações aqui analisadas.

Ao final do ano de 2019, 16 professores em formação inicial - oito de cada um dos programas haviam planejado e ministrado aulas por, pelo menos, um bimestre, em turmas do $9^{\circ}$ ano da rede municipal, vivenciando sabores e dissabores de lidar com a Prova Brasil em sala de aula. Nesse processo, os cinco professores da Educação Básica tiveram a possibilidade de planejar, ministrar e supervisionar aulas e ainda refletir sobre situações que se inspiravam no discurso da mudança e não tangenciavam o trabalho com os descritores da Prova Brasil, algo que, provavelmente, alguns não vislumbravam como possível.

\section{Considerações Finais}

Produto do neoliberalismo, a Prova Brasil pode desencadear, no ensino e na formação de professores, ações típicas desse pensamento econômico. Na disciplina Língua Portuguesa, por exemplo, as práticas propostas pelo discurso da mudança que envolvem o uso (leitura/escuta e produção de textos) e a reflexão (análise linguística) podem acabar substituídas apenas pelo treinamento para responder questões de múltipla escolha, o que, consequentemente, pode gerar a compartimentação das atividades dessa disciplina e não a integração entre os eixos em que se assenta(m) o(s) seu(s) objeto(s) de ensino.

Nesse contexto neoliberal, o professor tende a ser entendido como o único responsável pelo sucesso (ou fracasso) dos alunos nas avaliações de larga escala e, por esse motivo, é visto como aquele profissional que deve, através de seus esforços individuais, buscar investir em sua formação para conseguir oferecer, em sua sala de aula, uma educação teoricamente de qualidade. Veladamente, isso ocasiona algumas competições entre escolas; afeta emocionalmente os docentes que acham que o resultado dos testes revela, de fato, a qualidade do trabalho ofertado; e leva, ainda que indiretamente, à separação entre alunos fortes e fracos, desconsiderando um conjunto de fatores, como as motivações pessoais e as condições sociais dos alunos para estarem na escola, os quais incidem na participação dos discentes ao longo do percurso formativo deles na Educação Básica.

Ainda nesse contexto, por vezes, as Secretarias de Educação supõem que o professor não é capaz de investir em sua formação e estabelecem acordos com empresas privadas de prestação de assessoria que, geralmente objetivando a venda de materiais didáticos e de treinamentos padronizados, são pouco sensíveis às diversas realidades escolares existentes no Brasil, como se a qualidade do ensino fosse melhorar 
repentinamente a partir da padronização de ações e de materiais e não por meio do investimento na formação continuada dos docentes, na melhoria da infraestrutura das escolas e na criação de condições para que o estar nesse ambiente educativo seja aprazível para professores e alunos.

Os dados por nós aqui apresentados apontam para a necessidade, a permanência e a consolidação das parcerias entre universidade, secretarias de educação e escolas públicas, uma vez que tais parcerias podem contribuir significativamente para a melhoria, de um lado, do ensino ofertado na rede básica, e de outro, da formação inicial e continuada de professores. Primeiro, porque se notou uma carência na rede pública de ensino de ações para o planejamento das atividades de Língua Portuguesa com vistas a uma melhor formação dos alunos e não apenas com o fito de cumprir com a realização do exame Prova Brasil e aumentar os números da escola; mas não necessariamente garantir a qualidade do ensino ofertado. Segundo, porque vimos a necessidade de a universidade ter espaços de atuação para os seus licenciandos vivenciarem situações reais de ensino e pensarem alternativas para as demandas surgidas em tais espaços, o que contribuirá para a formação de profissionais com mais autonomia na reflexão e na execução de ações didáticas. Terceiro, a parceria entre universidade, secretaria de ensino e escolas públicas traz alguns impactos positivos que incidem diretamente na reflexão, e possível alteração, sobre o currículo que as escolas seguem, na ressignificação das práticas por parte dos docentes, nas alterações do planejamento didático, na elaboração de atividades e na descentralização do livro didático como único instrumento para o professor.

No que diz respeito à formação de professores na perspectiva que defendemos, a parceria entre universidade e Educação Básica é fundamental, pois permite que diversos olhares e esforços tenham resultados mais consistentes. Nesse processo, as dificuldades de comunicação e os conflitos são entendidos como aspectos constitutivos da interação entre essas duas instituições (SIGNORINI, 2000). Para que essa parceria continue a existir, é necessária a defesa de alguns aspectos do trabalho do professor que têm sido precarizados.

Nesse sentido, é vital que as atividades de pesquisa e de extensão das universidades continuem a ser fomentadas, inclusive financeiramente, e que elas continuem a ser contabilizadas como parte da carga horária dos professores. Nos últimos anos, há o crescimento de uma visão, no senso comum e em alguns setores políticos, bastante equivocada, que entende que o trabalho do docente do Ensino Superior se restringe às atividades de ensino em sala de aula. As ações apresentadas neste texto demonstram a indissociabilidade entre as atividades de ensino, pesquisa e extensão das instituições universitárias. Além disso, a formação continuada dos professores da Educação Básica deve ser promovida pelos gestores estaduais e municipais como parte da carga horária desses profissionais, e não como mais uma atividade a ser feita após a já longa jornada de trabalho.

No que diz respeito à relação formação do professor e ensino de Língua Portuguesa, é necessário repensar os objetos de ensino da disciplina de Língua Portuguesa de forma que se passe a distinguir com mais clareza e objetividade o que precisa ser essencial do que é acessório. Isso faz com que o docente volte a aprender que o seu trabalho em sala de aula deve estar a serviço da formação dos alunos e não dos interesses neoliberais que fazem da educação uma mercadoria bastante lucrativa para quem detém as condições e os meios de explorar esse mercado e, consequentemente, o trabalho docente. Despertar tal consciência poderá fazer com que os docentes possam se desvencilhar da estandardização do mercado e voltarem a ter para si a autonomia e o lugar de autoridade para selecionar, organizar e socializar o processo de conhecimento, sem que para isso tenham de recorrer ao auxílio de instituições privadas que produzem "apostilas estandardizadas, transformando os professores em 'entregadores de conhecimento"' (FRIGOTTO, 2012, p. 9). Esse impulso para a autonomia foi, a nosso ver, um dos maiores ganhos para os docentes com os quais trabalhamos. Entretanto, a manutenção de tal autonomia exige que as ações em parceria realizadas entre universidade e escolas sejam permanentes, a fim de que o trabalho iniciado não regrida.

Enfim, as ações, aqui analisadas, de ensino, pesquisa e extensão que desenvolvemos no munícipio da região na qual está localizado o CCHE da UEPB não pregam o fim da Prova Brasil, mas buscam estabelecer 
uma nova lógica de convívio com essa avaliação de larga escala. Conforme evidenciado, a abordagem desenvolvida no período de 2015 a 2019 teve como meta o ensino de Língua Portuguesa em uma perspectiva holística semelhante à proposta inicialmente pensada por um círculo acadêmico no final da década de 70 do século XX e, depois, assumida como discurso oficial (BRASIL, 1998, 2017). Nessa lógica, que se opõe à perspectiva neoliberal, não se ensina apenas para o teste (VOLANTE, 2004) e se acredita que um bom resultado na Prova Brasil é consequência de uma educação verdadeiramente de qualidade, e não a única meta a ser atingida.

\section{REFERÊNCIAS}

ALKMIM, T. M. Sociolinguística - Parte I. In: MUSSALIM, F.; BENTES, A. C. (org.). Introdução à Linguística: domínios e fronteiras. v. 1. 6. ed. São Paulo: Cortez, 2011. p. 21-47.

BACKES, J. L.; PAVAN, R. (org.). A universidade vai à escola pública em tempos de avaliação em larga escala: práticas, potências e subversões. Campinas: Mercado de Letras, 2018.

BENTES, A. C. Linguística Textual. In: MUSSALIM, F.; BENTES, A. C. (org.). Introdução à Linguística: domínios e fronteiras. v. 2. 6. ed. São Paulo: Cortez, 2011. p. 245-287.

BRASIL. Ministério da Educação. Parâmetros Curriculares Nacionais - Terceiro e Quarto Ciclos do Ensino Fundamental: Língua Portuguesa. Brasília: MEC/SEF, 1998.

BRASIL. Ministério da Educação. Prova Brasil - ensino fundamental: matrizes de referências, tópicos e descritores. Brasília: MEC, SEB; Inep, 2008.

BRASIL. Ministério da Educação. Base Nacional Comum Curricular. Brasília: MEC, 2017.

BUNZEN, C. A fabricação da disciplina escolar Português. Revista Diálogo Educacional, Curitiba, v. 11, n. 34, p. 855-911, 2011.

CARVALHO, R. S. de. Ensinar a ler, aprender a avaliar: avaliação diagnóstica das habilidades de leitura. São Paulo: Parábola, 2018.

FRIGOTTO, G. Prefácio. In: OLIVEIRA, D. M. (org.). Formação continuada de professores: contribuições para o debate. Juiz de Fora: Editora da UFJF, 2012. p. 7-9.

GENTILI, P. Neoliberalismo e Educação: manual do usuário. In: GENTILI, P.; SILVA, T. T. da (org.). Escola S.A.: quem ganha e quem perde no mercado educacional do neoliberalismo. 2. ed. Brasília: CNTE, 1999. p. 9-49.

GERALDI, J. W. Unidades básicas do ensino de português. In: GERALDI, J. W. (org.). O texto na sala de aula. 5. ed. São Paulo: Ática, 2011. p. 59-79.

GERALDI, J. W. (org.). O texto na sala de aula. 5. ed. São Paulo: Ática, 2011.

KOCH, I.; ELIAS, V. M. Ler e compreender: os sentidos do texto. São Paulo: Contexto, 2008.

MATÊNCIO, M. L. M. Estudo da lingua falada e aula de língua materna: uma abordagem processual da interação professor/aluno. Campinas: Mercado de Letras, 2001. 
MUSSALIM, F. Análise do Discurso. In: MUSSALIM, F; BENTES, A. C. (org.). Introdução à Linguística: domínios e fronteiras. v. 1. 6. ed. São Paulo: Cortez, 2012. p.113-165.

PEREIRA, B. A. O debate no ensino de português: do livro didático à sala de aula. 2011. Dissertação (Mestrado em Linguagem e Ensino) - Universidade Federal de Campina Grande, Campina Grande, 2011.

PIETRI, É. de. A constituição do discurso da mudança no ensino de língua portuguesa. 2003. Tese (Doutorado em Linguística Aplicada) - Universidade Estadual de Campinas, Campinas, 2003.

UFMG - Universidade Federal de Minas Gerais. Faculdade de Educação. Grupo de Avaliação e Medidas Educacionais. A avaliação externa como instrumento da gestão educacional dos estados. São Paulo: Fundação Victor Civita, 2011.

SCHNEUWLY, B.; DOLZ, J. Des objets enseignés en classe de français. Rennes Cedex: Presses Universitaires de Rennes, 2009.

SIGNORINI, I. A interação entre universitários/alfabetizador em programas de formação em serviço: ação entre díspares ou comunicação entre pares? In: KLEIMAN, A.; SIGNORINI, I. (org.). O ensino e a formação do professor. Porto Alegre: Artmed, 2000. p. 244-261.

SIGNORINI, I. Letramento e inovação no ensino e na formação do professor de língua portuguesa. In: SIGNORINI, I. (org.). Significados da inovação no ensino de lingua portuguesa e na formação de professores. Campinas: Mercado de Letras, 2007. p. 211-228.

SILVA, D. F. da. O efeito retroativo da Prova Brasil de Lingua Portuguesa nos anos finais do ensino fundamental em uma rede municipal paraibana. 2019. Trabalho de Conclusão de Curso (Licenciatura em Letras) - Universidade Estadual da Paraíba, Monteiro, 2019.

SILVA, F. K. L. da. Professores de português em formação inicial e o desafio de abordar a Prova Brasil nas salas de aula da Educação Básica. 2019. Trabalho de Conclusão de Curso (Licenciatura em Letras) - Universidade Estadual da Paraíba, Monteiro, 2019.

SOARES, M. Português na escola: história de uma disciplina curricular. In: BAGNO, M. (org.). Lingüística da norma. São Paulo: Loyola, 2002. p. 155-177.

VOLANTE, L. Teaching to the test: what every educator and policy-maker should know. Canadian Journal of Educational Administration and Policy, Saskatchewan, n. 35, p. 1-6, Sep. 2004. 